\title{
Correlation Between Ability on Playing Tetris and GPA
}

\author{
Aprilia Ratna Christanti, Yulianto Tejo P. \\ Department of Information System \\ Soegijapranata Catholic University, Semarang, Indonesia \\ vincencia.ratna@gmail.com
}

\begin{abstract}
The goal of this study is to determine the correlation between ability on playing Tetris and GPA of Soegijapranata Catholic University, Department of Information System students against the dexterity in playing Tetris. The research has been done using experiment method on ten Information System students who have various grade points. They played Tetris, 30 minutes each, for three consecutive days. The results showed that: First, eight out of the ten students improved their agility. It can be seen from the increasing scores and levels; Second, the coefficient correlation between student grade point and dexterity in playing Tetris is by $62 \%$.
\end{abstract}

Keywords - Ability, grade point average, Tetris

\section{INTRODUCTION}

For game community, Tetris game is pretty familiar. This is because the Tetris game has been around since 1985. At this time, however, this game is already considered oldfashioned.

Even though this game is considered old-fashioned and ancient, the game is still in demand until now. It had even received an award in $100^{\text {th }}$ Electronic Gaming Monthly news. Tetris was the first rank of the "Best Games All the Time”. Even in 2007, Tetris was on the second rank of the "100 Best Games All the Time" by IGN.

Most ordinary people assume that Tetris is an unimportant, boring, and wastingtime kid's game. However, this game actually has a different appeal and it is very useful in improving the brain ability and lining of the brain (cortex) will be developed. The impact is that people are able to think critically and solve complex things.

This refers to the results of a study conducted by the Mind Research Network. This study was the first MRI scanning technology performed to investigate how the game influenced the brain.

Precision is required in this Tetris. This is not separated from how to play Tetris that requires cognitive processes like attention, hand-eye coordination, and memory which worked simultaneously.

Based on those things, Tetris could boost brain abilities, so people are capable to think critically and complex. Of course, most of public think that only intelligent people are able to earn higher score while playing Tetris.

The following article will discuss whether there is a correlation between academic ability (GPA) and the ability or dexterity in playing Tetris.

\section{THEORETICAL BASIS}

Tetris is a puzzle-building game that was firstly designed by Alexey Pajitnov in June 1985. At that time, he worked at the Dorodnicyn Computer Center in the USSR Academy of Sciences in Moscow. The name, Tetris, itself was taken from the Greek numerical language, namely tetra which means four. Four is the sum beam arrangements that can be changed into different shapes so it can interlock to each other.

Basically, there are seven types of beam formation in the Tetris game; there are I, $\mathrm{J}, \mathrm{L}, \mathrm{O}, \mathrm{S}, \mathrm{T}$, and $\mathrm{Z}$. The blocks are named so 
because it looks alike with the letters. For more details, please see the table below.

Table 2.1 Forms of Beams

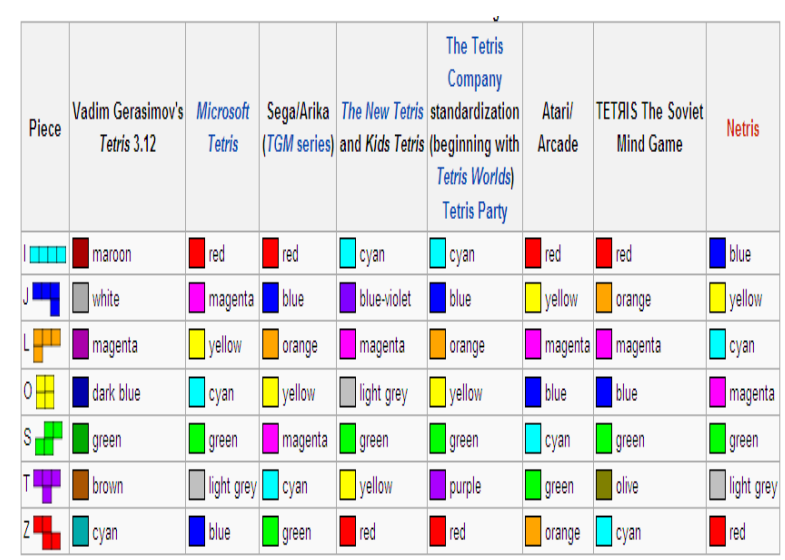

(source:

http://sekedartahu.blogspot.com/2010/06/sejarah-danasal-usul-game-tetris.html )

The player can control the falling Tetris blocks through four different types of control: move the beam to the left, move the beam to the right, increase the speed of the falling beam, and rotate the falling beam $90^{\circ}$ clockwise (it also change the shape of the beam).

The objective of this game is to steer the falling beam towards arranged beams that had fallen earlier, so that the beams can be formed into a full line. Each full line will be removed from the pile and the pile over the top will replace the removed complete pile. If the pile reaches the upper limit, then the game is over.

The higher level will perform faster falling beams. Players are required to think quickly in placing various blocks in the appropriate places.

\section{RESEARCH METHODOLOGY}

A previous study conducted by the Mind Research Network, proved that the Tetris game is useful to increase the brain ability so it will enable its player to think critically and solve complex thing.
Many people assume that only intelligent person who is capable to critical thinking in academic and complex ways that typically obtain higher scores while playing Tetris. The fact os some people who are not capable of academic also can even play Tetris better.

To prove this claim, the author did a research with an experiment method on ten students of Information System Soegijapranata Catholic University who have a grade point average ranging from highest to lowest. The students will play Tetris for 30 minutes each day for three consecutive days.

\section{III.1 Research}

Table 3.1 Research Tetris Game

\begin{tabular}{|c|c|c|c|c|}
\hline \multirow{3}{*}{ Day } & \multicolumn{4}{|c|}{ Level with the best score } \\
\hline & \multicolumn{2}{|c|}{$\mathbf{A}$} & \multicolumn{2}{|c|}{ B } \\
\hline & Level & Score & Level & Score \\
\hline I & 6 & 15358 & 6 & 13388 \\
\hline II & 7 & 21957 & 6 & 17018 \\
\hline III & 8 & 17666 & 7 & 17572 \\
\hline \multicolumn{2}{|c|}{ Total Score } & 54981 & & 47978 \\
\hline
\end{tabular}

\begin{tabular}{|c|c|c|c|c|}
\hline \multirow{2}{*}{ Day } & \multicolumn{4}{|c|}{ Level with the best score } \\
\cline { 2 - 5 } & \multicolumn{2}{|c|}{ C } & \multicolumn{2}{c|}{ D } \\
\cline { 2 - 5 } & Level & Score & Level & Score \\
\hline I & 3 & 6281 & 6 & 9967 \\
\hline II & 5 & 8960 & 6 & 11299 \\
\hline III & 5 & 11732 & 8 & 15801 \\
\hline \multicolumn{2}{|c|}{ Total Score } & 26973 & & 37067 \\
\hline
\end{tabular}

\begin{tabular}{|c|c|c|c|c|}
\hline \multirow{4}{*}{ Day } & \multicolumn{3}{|c|}{ Level with the best score } \\
\cline { 2 - 5 } & \multicolumn{2}{|c|}{ E } & \multicolumn{2}{c|}{ F } \\
\cline { 2 - 5 } & Level & Score & Level & Score \\
\hline
\end{tabular}




\begin{tabular}{|c|c|c|c|c|}
\hline I & 6 & 10929 & 5 & 9554 \\
\hline II & 6 & 12358 & 8 & 18655 \\
\hline III & 7 & 14915 & 8 & 23755 \\
\hline \multicolumn{2}{|r|}{ Total Score } & 38202 & \multicolumn{2}{|c|}{51964} \\
\hline
\end{tabular}

\begin{tabular}{|c|c|c|c|c|}
\hline \multirow{2}{*}{ Day } & \multicolumn{4}{|c|}{ Level with the best score } \\
\cline { 2 - 5 } & \multicolumn{2}{|c|}{ G } & \multicolumn{2}{c|}{ H } \\
\cline { 2 - 5 } & Level & Score & Level & Score \\
\hline I & 6 & 3275 & 9 & 21879 \\
\hline II & 6 & 4165 & 9 & 22834 \\
\hline III & 6 & 2903 & 10 & 27354 \\
\hline \multicolumn{2}{|c|}{ Total Score } & 10343 & & 72064 \\
\hline
\end{tabular}

\begin{tabular}{|c|c|c|c|c|}
\hline \multirow{2}{*}{ Day } & \multicolumn{4}{|c|}{ Level with the best score } \\
\cline { 2 - 5 } & \multicolumn{2}{|c|}{ I } & \multicolumn{2}{c|}{ J } \\
\cline { 2 - 5 } & Level & Score & Level & Score \\
\hline I & 7 & 16713 & 8 & 29983 \\
\hline II & 9 & 30041 & 13 & 64662 \\
\hline III & 9 & 38021 & 12 & 62214 \\
\hline \multicolumn{2}{|c|}{ Total Score } & 84775 & & 156859 \\
\hline
\end{tabular}

Sources: The results of the data processing itself, 2014

Specification grade point average:
$\begin{array}{llll}\text { A: } 1,77 & \text { B: } 2,1 & \text { C: } 2,27 & \text { D: } 2,56 \quad \text { E: } 2,6\end{array}$

F: 3,12 G: $3,2 \quad$ H: $3,4 \quad$ I: $3,73 \quad$ J: 4,0

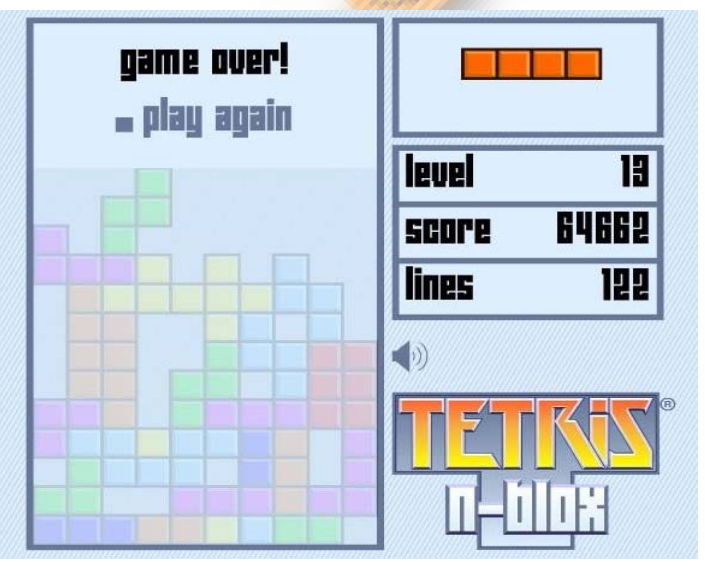

Fig. 3.1 Tetris Game of Player $\mathbf{J}$ Table 3.2 Total Score based on GPA Players

\begin{tabular}{|c|c|c|c|c|c|}
\hline IPK & 1,77 & 2,1 & 2,27 & 2,56 & 2,6 \\
\hline $\begin{array}{c}\text { Total } \\
\text { Score }\end{array}$ & 54981 & 47978 & 26973 & 37067 & 38202 \\
\hline
\end{tabular}

\begin{tabular}{|c|c|c|c|c|c|}
\hline IPK & 3,12 & 3,2 & 3,4 & 3,73 & 4,0 \\
\hline $\begin{array}{c}\text { Total } \\
\text { Score }\end{array}$ & 51964 & 10343 & 72064 & 84775 & 156859 \\
\hline
\end{tabular}

\section{RESULTS AND DISCUSSION}

Based on the table above, eight out of ten students of Information System who have played Tetris generally improved their agility day by day. It can be seen from the increasing scores and levels.

The results of the author's experiment showed that the highest grade point belongs to player $\mathrm{J}$ who has a 4.0 grade point average, successfully achieved the highest score and better level than any other students who have lower grade point. However, not all students who have lower GPA achieved bad score. For example, player A with the lowest GPA $(1,77)$ played much better than player $G$ with a higher GPA.

With a linear regression, an equation obtained is as follow:

$$
\mathrm{y}=34671,329 \mathrm{x}-41559,47
$$

Correlation coefficient: $r=62,24 \%$

Explanation: $\mathrm{y}=$ total score

$$
\mathrm{x} \text { = grade point average }(\mathrm{GPA})
$$

It shows that academic ability does not significantly affect someone's dexterity in playing Tetris because the correlation is only $62 \%$. Although in this study player $\mathrm{J}$ who has the highest GPA also managed to obtain the highest score.

This situation shows that academic ability is dominantly controlled by left brain; meanwhile dexterity in playing Tetris is more associated with imagination controlled by right 
brain. This finding corresponds with the theory of functions of the left brain and the right brain that has been popular since the 1960s, the research conducted by RS. Roger Sperry.

The left brain functions in terms of dealing with logic, reason, ability to write and read, as well as the math center often called the central Intelligence Quotient (IQ). While the right brain functions in the development of Emotional Quotient (EQ), such as socialization, communication, interaction and emotional control.

This game requires a balance between the right brain and the left brain. The right brain in attention, coordination of hand and eye, and the left brain controls memory required to think quickly in placing the Tetris blocks in a proper place.

\section{CONCLUSIONS}

One's ability to play Tetris and score achievement is not significantly affected by the player's grade point. Agility in playing Tetris can be obviously developed. The game requires a balance between the right and left brain, and therefore it can hone/sharpen the brain ability to obtain the best score.

This present research is modest and limited. There were only ten students participating. Hopefully, a similar research on the same topic will be carried out more accurately in the future. It can be done in a wider environment such as taking samples of the elementary graders, junior high school graders, senior high school graders, or age group with regard to academic achievement to proving how much the correlation between academic skills with dexterity in playing Tetris.

\section{ACKNOWLEDGMENT}

I am so proud and grateful for the scholarship of Beasiswa Unggulan from Bureau for Planning and International Corporation, the Ministry of Education and Culture of Indonesia which already gave me a trust to receive this scholarship. This scholarship is a great help in my studying process in the world of game development.

\section{REFERENCES}

[1] TTC. What is the Tetris Game (Online). http:/ www.tetris.com/history/index.aspx, accessed on 23-11-2013

[2] Webber, Charlotte. Is Tetris Good for the Brain (Online).

http://www.biomedcentral.com/presscenter/pressreleases 20090901b, accessed on 25-11-2013

[3] Yaacob, Sobri. Panduan: Perbezaan Otak Kiri dan Otak Kanan (Online).

http://akusobriyaacob.blogspot.com/2011/09/perbezaanotak-kiri-dan-otak-kanan.html, accessed on 25-04-2013

[4] F.P., Erwin Eka. Perbedaan Otak Kiri \& Otak Kanan (Online). http://www.terapimusik.com/otak_kanan.htm, accessed on 25-04-2013 